\title{
Active composite starch films containing green synthetized silver nanoparticles
}

\author{
Florencia Ortega ${ }^{a}$, Leda Giannuzzi a, Valeria B. Arce ${ }^{b}$, M. Alejandra García ${ }^{\text {a, * }}$ \\ a CIDCA (Centro de Investigación y Desarrollo en Criotecnología de Alimentos), Facultad de Ciencias Exactas-Universidad Nacional de La Plata - Centro \\ Científico Tecnológico La Plata (CCT-La Plata) CONICET- CICPBA- 47 y 116 S/N ${ }^{o}$, La Plata B1900AJJ, Buenos Aires, Argentina \\ ${ }^{\mathrm{b}}$ CIOP (Centro de Investigaciones Ópticas), CONICET La Plata - CIC - UNLP, CC 3, 1897 Gonnet, La Plata, Argentina
}

\section{A R T I C L E I N F O}

\section{Article history:}

Received 2 December 2016

Received in revised form

1 March 2017

Accepted 1 March 2017

Available online 5 April 2017

\section{Keywords:}

Starch film

Silver nanoparticle

Green synthesis

Antimicrobial film

\begin{abstract}
A B S T R A C T
The aims of this work were to couple both the silver nanoparticles (AgNPs) synthesis, and filmogenic suspensions preparation, to characterize the obtained AgNPs and the derived nanocomposite films studying their antimicrobial capacity and developing an active packaging. One of the new approaches to this work is the use of low concentrations of AgNPs at which no adverse cytotoxic effects have been observed. Nanoparticles were characterized by spectrophotometric techniques and electron microscopy, finding that they are spherical with diameters varying between 5 and $20 \mathrm{~nm}$ and detecting the formation of agglomerates. The addition of AgNPs did not affect the filmogenic capacity of gelatinized starch suspension. The content of AgNPs caused a slight increase in film thickness and opacity, keeping the material UV-barrier capacity. A decrease in water vapor permeability with increasing AgNPs concentration was observed. Besides, AgNPs allow the matrix reinforcement, developing a more resistant and tough material, with smooth and homogeneous surfaces, as evidenced by SEM, and maintaining their heat sealing capacity. Nanocomposite films containing AgNPs concentrations greater than $71.5 \mathrm{ppm}$ inhibited the growth of E. coli ATCC and Salmonella spp., which are responsible for most foodborne diseases. However, films containing $143 \mathrm{ppm}$ AgNPs were selected since they better maintained their integrity to microbial attack. These active films were able to extend the shelf-life of fresh cheese samples for 21 days. Thus, it was possible to develop and characterize nanocomposite films based on corn starch and containing AgNPs, which confers them antimicrobial properties.
\end{abstract}

๑) 2017 Elsevier Ltd. All rights reserved.

\section{Introduction}

The great industrial demand and the application of nanotechnology lead to the development of a new kind of packaging materials such as biobased nanocomposites. These consist of a biodegradable polymer matrix reinforced with a material at the nanoscale (1-100 nm), which improves the mechanical, thermal, optical and physicochemical properties compared to the pure polymer matrix (Kanmani \& Rhim, 2014a; Kuorwel, Cran, Orbell, Buddhadasa, \& Bigger, 2015; Rhim, Park, \& Hac, 2013a). Among the most cited biodegradable nanocomposites, those containing starch and clay are the most studied (Abreu et al., 2015; Cheviron, Gouanvé, \& Espuche, 2014, Cheviron, Gouanvé, \& Espuche, 2015, Cheviron, Gouanvé, \& Espuche, 2016; Olivato et al., 2017),

\footnotetext{
* Corresponding author.

E-mail address: magarcia@quimica.unlp.edu.ar (M.A. García).
}

although other biopolymer matrices have been used, such as chitosan (Rhim, Hong, Park, \& Perry, 2006), agar (Ghosh et al., 2010; Rhim, Wang, \& Hong, 2013), proteins (Kanmani \& Rhim, 2014b), or their combination (Kanmani \& Rhim, 2014a; Yoksan \& Chirachanchai, 2010).

Recently, nanocomposites with antimicrobial activity have been studied as active packaging for application in the food industry in order to eliminate or reduce the growth of pathogens responsible for foodborne diseases (Kuorwel et al., 2015; Rhim, Park, et al., 2013; Rhim, Wang, et al., 2013). A variety of metal nanoparticles, such as gold, silver, copper, or their oxides have been included in nanocomposites formulations. However silver nanoparticles (AgNPs) are the most commonly used due to their optical, catalytic, thermal and electrical stability properties (Rhim, Wang, \& Hong, 2013b). Likewise, AgNPs reinforce biopolymer matrices and confers them antimicrobial capacity over a broad spectra of bacteria, viruses and fungi (Kim et al., 2007; Zhang, Peng, Huang, Zhou, \& Yan, 2008). 
Chemical synthesis is the major process used for obtaining controlled shape and size AgNPs. Generally it proceeds from the reduction of a silver salt using a chemical reducing agent in the presence of a stabilizer (Daniel \& Astruc, 2004; Masala \& Seshadri, 2004). Nowadays, there is an increase in the development of green eco-friendly synthesis, which is based on the use of non-toxic solvents, reducing agents and stabilizers which do not harm the environment (Raveendran, Fu, \& Wallen, 2003; Vigneshwaran, Nachane, Balasubramanya, \& Varadarajan, 2006). In this sense, Oluwafemi, Vuyelwa, Scriba, and Songca (2013) have reported a stable controlled synthesis which led to small-size nanoparticles with high monodispersity, utilizing maltose, a GRAS nontoxic disaccharide, as reducing agent in the presence of starch as stabilizer. In this method small AgNPs $(\leq 5 \mathrm{~nm}$ ) coated with a starch layer are formed. Several authors have reported that spherical and small AgNPs obtained by a completely green chemical process show good antimicrobial properties even when they were used in low (mM) concentrations (Abreu et al., 2015; Cheng, Betts, Kelly, \& Hector, 2015; Cheng, Betts, Kelly, Schallerb, \& Heinze, 2013; Cheviron et al., 2014).

The aims of this study were to couple the AgNPs synthesis to the filmogenic suspension preparation, to characterize both the AgNPs and the nanocomposite materials obtained studying their antimicrobial capacity and application as active packaging.

\section{Materials and methods}

\subsection{Materials}

Silver nitrate $\left(\mathrm{AgNO}_{3}\right.$, p.a., CAS [7761-88-8]) and maltose (pure, Art. 9798.05) were purchased from Biopack (Biopack, Buenos Aires, Argentina). Native corn starch containing 25\% amylose was provided by Unilever (Unilever, Buenos Aires, Argentina). Glycerol (Anedra, Buenos Aires, Argentina) was used as plasticizer in all formulations. Ultrapure water with a specific resistance of $18 \mathrm{M} \Omega$ was obtained by reverse osmosis by filtration and ion-exchange (OSMOION5-2, APEMA).

\subsection{Nanoparticles synthesis coupled to filmogenic suspension preparation}

Silver nanoparticles (AgNPs) synthesis was carried out in situ in the filmogenic suspensions, according to the method proposed by Oluwafemi et al. (2013) with some modifications. This procedure allows coupling both processes, taking advantage of the starch filmogenic suspension as dispersive medium of the synthesized AgNPs.

For this purpose $3 \% \mathrm{w} / \mathrm{v}$ corn starch aqueous suspensions were prepared and gelatinized at $78{ }^{\circ} \mathrm{C}$ for $20 \mathrm{~min}$, leading to gelatinized filmogenic suspensions. To obtain nanocomposites systems $10 \mathrm{ml}$ solution of $\mathrm{AgNO}_{3}$ were added to gelatinized filmogenic suspensions. The concentration of $\mathrm{AgNO}_{3}$ used was such that the final concentration of $\mathrm{Ag}$ in the filmogenic suspensions was 5, 10, 25 and $50 \mu \mathrm{M}$. The AgNPs concentrations were selected considering cytotoxic studies conducted on fibroblasts and osteoblasts (Flores et al., 2013; Hackenberg et al., 2011; Marambio-Jones \& Hoek, 2010). Conforming to these studies concentrations up to $75 \mu \mathrm{M}$ were within the limits of cytotoxic safety, so in the present work concentrations up to $50 \mu \mathrm{M}$ were used. Additionally, Ghosh et al. (2010) reported that the AgNPs exhibited a very low level of toxicity $(72 \mu \mathrm{g} / \mathrm{ml}$ ) and beyond this concentration of AgNPs a drastic reduction of cells viability was observed.

Then $20 \mathrm{ml}$ of $1.310^{-3} \mathrm{M}$ maltose solution as reductor agent were incorporated guaranteeing an excess with respect to the $\mathrm{AgNO}_{3}$ concentration used. The same maltose solution concentration was used for all trials. Control films (without AgNPs) were prepared in a similar way replacing $\mathrm{AgNO}_{3}$ solution by $10 \mathrm{ml}$ of ultrapure water in order to simulate the whole process. The system was kept under constant stirring for $20 \mathrm{~min}$ at $78{ }^{\circ} \mathrm{C}$, to achieve the formation of AgNPs.

After that, the gelatinized suspensions were cooled to $50{ }^{\circ} \mathrm{C}$ and glycerol as plasticizer was added in a concentration of $30 \% \mathrm{w} / \mathrm{w}$, relative to the mass of starch in the nanocomposite filmogenic suspension. The concentration of plasticizer used was optimized in previous studies (López, Giannuzzi, Zaritzky, \& García, 2013).

\subsection{Characterization of silver nanoparticles}

\subsubsection{UV-vis absorption}

In order to improve their visualization, AgNPs were synthesized using a lower concentration of corn starch $(1 \% \mathrm{w} / \mathrm{v})$ and higher concentration of $\mathrm{AgNO}_{3}(500 \mu \mathrm{M})$, following the procedure described by Oluwafemi et al. (2013). The system was kept under constant stirring at $78{ }^{\circ} \mathrm{C}$ for $1 \mathrm{~h}$, and then aliquots of $5 \mathrm{ml}$ were taken every 10 min to follow the development of the AgNPs. The UV-visible absorption spectrum was recorded over the wavelength range from 200 to $800 \mathrm{~nm}$ using a T90 + UV/vis Spectrometer (PG Instruments, USA). A suspension of $1 \% \mathrm{w} / \mathrm{v}$ corn starch treated as described previously was used as reference.

\subsubsection{Transmission electron microscopy (TEM)}

Size and shape of silver nanoparticles were evaluated using a JEM 1200EX II, Jeol transmission electron microscopy (Jeol, Japan) operating at $80 \mathrm{kV}$ equipped with an Erlangshen ES1000W, Model 785 (Gatan Inc., Pleasanton, California, USA) camera.

\subsubsection{Field emission - scanning electron microscopy (FE-SEM)}

The characterization of AgNPs was completed using a Field Emission - Scanning Electron Microscopy (FE-SEM) Supra ${ }^{\mathrm{TM}} 40$ (Germany) equipped with electron gun emission field, a third generation Zeiss GEMINI ${ }^{\circledR}$ column and a detector In-Lens. The accelerating voltage used was $3.00 \mathrm{kV}$.

\subsection{Preparation of nanocomposite films}

Films were prepared by casting $20 \mathrm{~g}$ nanocomposite filmogenic suspensions onto Petri dishes $\left(9 \mathrm{~cm}\right.$ diameter) and dried at $50^{\circ} \mathrm{C}$ in an oven until reaching constant weight (approximately $5 \mathrm{~h}$ ). The obtained films were removed from the dishes and conditioned (4 days at $70 \%$ relative humidity and $25{ }^{\circ} \mathrm{C}$ ) prior to the determinations of the physicochemical, optical, barrier and mechanical properties.

The final concentration of AgNPs in the film was 14.3, 28.6, 71.5 and $143 \mathrm{mg}$ of $\mathrm{Ag}$ per $\mathrm{kg}$ dried film (ppm) for filmogenic suspensions containing 5, 10, 25 and $50 \mu \mathrm{M} \mathrm{AgNO}_{3}$.

Film thickness was measured using a digital ultrasonic thickness gauge meter CM-8822 (New York, USA), for nonconductive materials on non-ferrous substrates. At least fifteen measurements were taken from each sample.

\subsection{Characterization of nanocomposite films}

\subsubsection{Optical properties}

Film color was measured using a Konica Minolta CR Serie 300 (Konica Minolta, Japan), calibrated with a standard $\left(L^{*}=97.54\right.$, $\left.\mathrm{a}^{*}=-0.03, \mathrm{~b}^{*}=1.74\right)$. The CIELab color scale was used, where $\mathrm{L}^{*}$ is the luminosity, $\mathrm{a}^{*}$ is the greenness and redness of samples and $\mathrm{b}^{*}$ represents the blueness and yellowness. Film specimens were placed on the white plate, and at least five measurements were taken from the sample surfaces. The CIELab scale was used to 
determined $a^{*}, b^{*}$ and $L^{*}$ parameters. Color differences were calculated according to López et al. (2013).

Films samples $(1 \mathrm{~cm} \times 3 \mathrm{~cm})$ were cut and put into a quartz cell, and the absorbance spectrum between 200 and $700 \mathrm{~nm}$ was registered using a T90 + UV/vis Spectrometer (PG Instruments, USA). The area under the curve between 200 and $400 \mathrm{~nm}$, expressed as absorbance units per nanometer ( $A U \mathrm{x} \mathrm{nm}$ ), estimated the UV-barrier capacity of films and those between 400 and $700 \mathrm{~nm}$ determined the film opacity according to Gontard, Guilbert, and Cuq (1992). Besides, film transparency was calculated as the absorbance value at $600 \mathrm{~nm}$ divided by film thickness and was expressed as $A_{600} / \mathrm{mm}$ (Zhang \& Han, 2006).

\subsubsection{Water vapor permeability}

Water vapor permeability (WVP) tests were conducted using ASTM method E96 with several modifications according to López, García, and Zaritzky (2008). Briefly, film samples were placed in acrylic permeation cells containing silica gel $(0 \% \mathrm{RH})$. The cells were weighed and put in airtight container equilibrated at $75 \% \mathrm{RH}$ with saturated $\mathrm{NaCl}$ solution and it was maintained at $20^{\circ} \mathrm{C}$. The driving force, expressed as water vapor partial pressure, was $1753.55 \mathrm{~Pa}$. After steady-state condition was reached, the acrylic permeation cells were weighed $(0.0001 \mathrm{~g})$ at initial time and at $1 \mathrm{~h}$ interval for $8 \mathrm{~h}$ and the changes in cell weight through time were determined. The linear regressions of the results were performed and the slope was calculated; then WVP $(\mathrm{g} / \mathrm{m} \mathrm{s} \mathrm{Pa})$ was obtained from the following equation:

$W V P=\frac{\left(\frac{\Delta w}{\Delta t}\right) \times \delta}{A \times \Delta p}$

where $(\Delta \mathrm{w} / \Delta \mathrm{t})$ is the slope of the weight vs time line expressed in $\mathrm{g} / \mathrm{s} ; \delta$, the film thickness in $\mathrm{m} ; \mathrm{A}$ is the exposed area $\left(1.81 \times 10^{-3} \mathrm{~m}^{2}\right)$, and $\Delta \mathrm{p}$ is the partial pressure difference of water vapor through the film. The informed values corresponded to the mean of at least two determinations.

\subsubsection{Film solubility and humidity}

Films samples were cut $(2 \mathrm{~cm} \times 2 \mathrm{~cm})$ and weighed (initial dry weight). Then, they were placed in beakers containing $80 \mathrm{ml} \mathrm{ul}$ trapure water and stirred at $200 \mathrm{rpm}$ during $1 \mathrm{~h}$. Finally the samples were recovered by filtration and dried at $105^{\circ} \mathrm{C}$ to constant weight (final dry weight). Then, film solubility (\%) was calculated as the percentage of total soluble matter. The solubility tests were carried out at 25 and $100{ }^{\circ} \mathrm{C}$ respectively.

Humidity content (\%) was determined by measuring the weight loss of films, upon drying in an oven at $105^{\circ} \mathrm{C}$ until constant weight.

In both cases, the reported results corresponded to the mean of at least two replicate assays.

\subsubsection{Mechanical properties}

Mechanical profiles (stress-strain curves) were obtained using a texturometer TA.XT2i-Stable Micro Systems (England) with a tension grip system A/TG. Nine rectangular probes of $0.6 \mathrm{~cm} \times 7 \mathrm{~cm}$ were tested at a strain rate of $5 \mathrm{~mm} / \mathrm{s}$ in the pre-test and $0.4 \mathrm{~mm} / \mathrm{s}$ in the assay. Tensile strength (TS, MPa), elasticity modulus (EM, $\mathrm{MPa}$ ) and elongation at break (EB, \%) were calculated as described in a previous work (López, Lecot, Zaritzky, \& García, 2011) according to the ASTM D882-91 method. Likewise, tensile energy at break (J) was obtained from the area under the stress-strain curve.

\subsubsection{Microstructure analysis}

Probes submitted to tensile tests were observed by SEM. The study was realized using a FEI QUANTA 200 SEM (Japan) with an
Apollo 40 electron detector, using an acceleration voltage of $10 \mathrm{kV}$. The samples were placed on bronze stubs with carbon doublesided tape and coated with a gold layer $(40-50 \mathrm{~nm})$ allowing visualization of surfaces and cross sections. The presence of AgNPs on the surface and cross section of the samples was checked with Xray dispersive spectroscopy (EDS) using an EDS microprobe and $\operatorname{EDAX}^{\circledR}$ detector (New Jersey, USA).

\subsection{Antimicrobial activity of nanocomposite films}

S. aureus ATCC, Salmonella spp. and E. coli ATCC bacterial strains as well as Penicillium spp. were selected as test microorganisms since they are mainly responsible of foodborne diseases. Bacterial inocula were prepared in Tryptone Soya Broth (TSB) and incubated at $37^{\circ} \mathrm{C}$ during $12 \mathrm{~h}$ until to reach a concentration of $10^{8}-10^{9} \mathrm{CFU} /$ $\mathrm{ml}$ determined by the solutions optical density (OD). Then, the inocula were diluted with $1 \%$ sterile peptone water (Oxoid). Penicillium spp. strain was prepared in potato dextrose agar at $37^{\circ} \mathrm{C}$.

Antimicrobial activity was studied by the agar disc diffusion method (Pranoto, Rakshit, \& Salokhe, 2005). Agar Mueller-Hinton (Merck) plates inoculated with $100 \mu \mathrm{l}$ of corresponding inoculum $\left(10^{4} \mathrm{CFU} / \mathrm{ml}\right)$ were used for bacterial tests. Meanwhile in the case of Penicillium spp, YGC (Yeast-Glucose-Chloramphenicol Extract; Merck) agar medium was used and in this case plates were inoculated with $100 \mu \mathrm{l}$ of $10^{2} \mathrm{CFU} / \mathrm{ml}$. In all cases, nanocomposite film discs of $2 \mathrm{~cm}$ diameter were cut and placed in direct contact with the agar Petri dishes. The samples were incubated at $37{ }^{\circ} \mathrm{C}$ and visual observations at 24, 48 and 72 h for E. coli ATCC, Salmonella spp. and S. aureus ATCC and 7 days of storage for Penicillium spp were carried out. Besides, assays were conducted at least by triplicate.

\subsection{Applications of active films}

\subsubsection{Heat-sealing capacity}

The heat-sealing capacity was studied on 143 ppm AgNPs films using an impulse-wire thermosealer (HermePlas, Argentina) on samples of $9 \mathrm{~cm}$ diameter. The thermosealer works at $220 \mathrm{~V}$ allowing set the temperature at $154.3 \pm 8.5{ }^{\circ} \mathrm{C}$, which was measured using a K-type thermocouple connected to a data logger thermometer (TES-1307, Taiwan).

Heat sealing resistance was evaluated using the above mentioned texturometer and A/TG tension grips onto nine rectangular probes of $0.6 \mathrm{~cm} \times 7 \mathrm{~cm}$. Mechanical patterns were registered and failure modes were assigned according to ASTM standard method F 88-00 (2001). The maximum tensile strength was informed in the case of failures near the zip, while for adhesive, cohesive o for delamination failures, media heat sealer resistance was determined. Both resistances were expressed in MPa. In the case of adhesive failures, the necessary energy to cause the failure was also calculated as the area under the curve and expressed in $\mathrm{J} /$ $\mathrm{m}$.

\subsubsection{Conservation of a dairy product}

Active nanocomposite films were used to package a dairy product, in order to evaluate their effectiveness as active packaging. For this purpose films containing 143 ppm AgNPs were selected. A soft cheese with high moisture content (46-55\%) was used. It was made from whole cow's milk, with a fat content of $45-60 \%$, matured in plastic film, vacuum packed and stored at a temperature below $8^{\circ} \mathrm{C}$ (data provided by the supplier). Regular portions of commercial soft cheese $(30 \mathrm{~g})$ were packed in the developed nanocomposite films and thermo-sealed, leading to nanocomposite bags. Due to García, Martino, and Zaritzky (2001) in previous work showed that films and coatings based on starch without addition of 
antimicrobial compounds did not provide any effective microbial barrier, the control samples were portions of soft cheese onto Petri dishes. Following the methodology proposed by López et al. (2013), all samples were put into synthetic bags of PD 141(CRYOVAC $\left.{ }^{\circledR}\right)$, a polyethylene multilayer material with $75 \mu \mathrm{m}$ thickness, and were stored at $4{ }^{\circ} \mathrm{C}$.

Yeast and molds were counted at initial time and after 7, 14, 21 and 28 days of refrigerated storage. $10 \mathrm{~g}$ of cheese samples were homogenized with $90 \mathrm{ml}$ of sterile peptone water $(0.1 \%)$ in a Stomacher Seward Model 400 (England). Then, $100 \mu \mathrm{l}$ of the homogenate was inoculated on YGC agar medium (Yeast extract, glucose, chloramphenicol) and incubated for 5 days at $37^{\circ} \mathrm{C}$. Viable microorganisms were determined by counting the number of colonies formed, and the results were expressed as $\mathrm{CFU} / \mathrm{g}$ cheese. All tests were done in triplicate and the reported results corresponded to the average of them.

\subsection{Statistical analysis}

A completely randomized experimental design was used to evaluate the properties and the antimicrobial capacity of active starch films. All experiments were performed at least in duplicates, with individually prepared and casted films as replicated experimental units as described previously in each determination. Systatsoftware (SYSTAT, Inc., Evanston, IL, USA) version 13.0 was used for multifactor analysis of variance as well as lineal and non lineal regressions. Differences in the properties of the films were determined by Fisher's least significant difference (LSD) mean discrimination test, using a significance level of $\alpha=0.05$.

\section{Results and discussion}

\subsection{Silver nanoparticles characterization}

Silver nanoparticles were obtained by redox reaction. Maltose was used as a reducing agent to facilitate the formation of the AgNPs, and starch was used as stabilizing agent during the formation. Different spectroscopic and microscopic techniques were used to characterize the obtained nanoparticles. UV-visible spectroscopy allows to investigate the formation and stability of AgNPs by the surface plasmon resonance (SPR) bands observable in the 400-450 nm region (Kerker, 1985; Slistan-Grijalva et al., 2005). Fig. 1a shows the UV-vis absortion spectra of AgNPs prepared. The presence of the characteristic plasmon evidenced by the peak at $425 \mathrm{~nm}$ confirmed the formation of AgNPs. The plasmon amplitude observed may be attributed to the interactions of NPs with the matrix or to the small aggregation. The hidrophilic $-\mathrm{OH}$ groups were responsible for the adsorption of starch in the surface of AgNPs through electrostatic interactions (Cheviron et al., 2014; Vigneshwaran et al., 2006).

The TEM micrograph showed that the silver nanoparticles were spherical with a mean diameter of $21 \pm 6.7 \mathrm{~nm}$ (Fig. 1b) determined with de software ImageJ based on the total count of 450 nanoparticles (Cheviron et al., 2014; Cheviron et al., 2015).

In order to estimate the dispersion of AgNPs in the gelatinized starch suspension, observations were made by scanning electron microscopy (SEM). In order to improve the visualization and characterization suspensions containing $1000 \mu \mathrm{M}$ AgNPs were observed. Fig. 1c shows that a uniform distribution of AgNPs into the polymeric matrix was obtained, in the micrographs nanoparticles can be visualized as white dots. Likewise, Fig. 1d evidences that the AgNPs tended to form agglomerates, probably due to the high concentration used in this assay.

\subsection{Nanocomposite films}

\subsubsection{Optical properties}

The addition of silver nanoparticles did not affect the filmogenic capacity of the corn starch suspension, obtaining homogeneous, colorless and transparent films that can be easily removed from the acrylic plate.

Both, color and either opacity or transparency, are important factors to consider in the development of food packaging materials, since optical properties can strongly influence the consumer's decision on product choosing. Surface color parameters values for the nanocomposite films are shown in Table 1 . The results indicate that the incorporation and concentration of AgNPs significantly $(p<0.01)$ affected chromaticity parameters $\left(a^{*}\right.$ and $\left.b^{*}\right)$, although in both cases the corresponding values were very low and visually nanocomposite films still remained colorless. The increase in the $b^{*}$ parameter could be attributed to the chemical browning reaction of maltose present in the matrix, which is the reducing agent required for the AgNPs synthesis. A clear trend with increasing AgNPs content was not observed, probably due to the lower concentrations used in the present work. Abreu et al. (2015) and Cheviron et al. (2014), reported a significant increase in this parameter and thus, the shift from milt transparent to a yellow/orange color for nanocomposite films containing concentrations up to $1 \mathrm{mM}$.

With regard to the luminosity $\left(\mathrm{L}^{*}\right)$, a significant effect $(p<0.01)$ was also found with the addition of NPs, observing a decrease in this parameter with increasing concentration. As expected, color difference $(\Delta \mathrm{E})$ was significantly $(p<0.01)$ affected by both the incorporation of AgNPs and their concentration. Once again the low values indicate that the developed films are almost colorless, correlating with film visual observations.

Films with the ability to absorb UV-light, allow to increase the foods shelf-life that can be altered by this radiation, such as those with high fat content. All nanocomposite films present UV-barrier capacity. Fig. 2a shows that this ability depend on the AgNPs content up to $28.6 \mathrm{ppm}$, while those containing higher concentrations resembled to control films.

Transparency is one of the main film features that affects its application and is critical when films are used for food coating or packaging. Besides, it has been pointed out as an index of polymer mixing capability in composite materials (Zolfi, Khodaiyan, Mousavi, \& Hashemi, 2014). Fig. 2 shows the film opacity and transparency values calculated from the absorption spectra obtained from the visible region. The AgNPs and their concentration did not significantly $(p>0.05)$ affect these parameters in developed materials. The obtained opacity values for nanocomposite films were in general closer to those reported for starch-based films. For example, Bertuzzi, Gottifredi, and Armada (2012) informed values between 160 and $320 \mathrm{AU} \times \mathrm{nm}$ for high amylose starch films. The obtained transparency values were similar to those of composite films formulated with collagen and waxy corn starch (Wang et al., 2017). According to García, Pinotti, and Zaritzky (2006), transparent films are characterized by low values of the area under the curve within the range of $400-800 \mathrm{~nm}$. On the other hand, films with higher opacity values, like those of AgNPs nanocomposite films, improve the ability of the films to protect the product contained in the package against light and enhance the quality of the packaged food.

\subsubsection{Water vapor permeability and solubility}

As it is well known, both WVP and water solubility depend on film thickness among other factors. Film thickness was significantly affected $(p<0.05)$ by AgNPs concentration, this result was in agreement with those reported by Kanmani and Rhim (2014a). In general, films with AgNPs presented higher thickness than control 

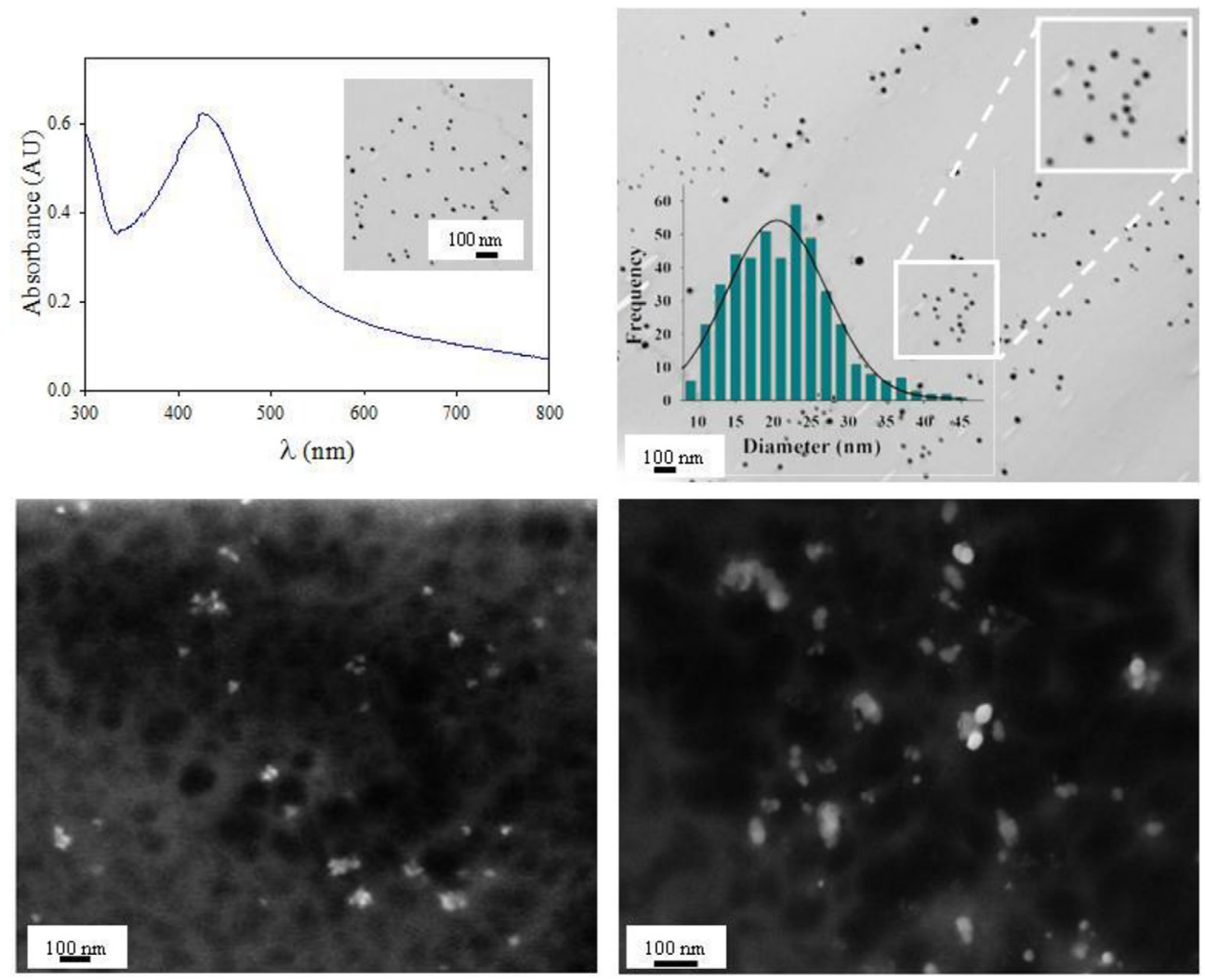

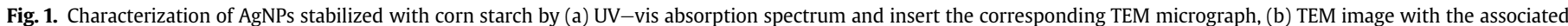
histogram. (c) and (d) show SEM micrographs of AgNPs embedded in starch matrix with different magnifications.

Table 1

Color parameters of nanocomposite and control corn starch films.

\begin{tabular}{|c|c|c|c|c|}
\hline AgNPs concentration in nanocomposite films (ppm) & Luminosity $\left(\mathrm{L}^{*}\right)$ & Chromaticity parameter $\mathrm{a}^{*}$ & Chromaticity parameter $\mathrm{b}^{*}$ & Color differences $(\Delta \mathrm{E})$ \\
\hline 0 & $97.44 \pm 0.09^{c}$ & $-0.38 \pm 0.01^{b}$ & $2.86 \pm 0.13^{\mathrm{a}}$ & $1.45 \pm 0.03^{\mathrm{a}}$ \\
\hline 14.3 & $97.36 \pm 0.10^{c}$ & $-0.36 \pm 0.06^{\mathrm{b}}$ & $3.12 \pm 0.15^{b}$ & $1.46 \pm 0.15^{\mathrm{a}}$ \\
\hline 28.6 & $96.76 \pm 0.05^{\mathrm{b}}$ & $-0.32 \pm 0.05^{\mathrm{b}}$ & $3.28 \pm 0.10^{\mathrm{b}}$ & $1.78 \pm 0.10^{\mathrm{b}}$ \\
\hline 71.5 & $96.62 \pm 0.07^{\mathrm{a}}$ & $-0.10 \pm 0.03^{\mathrm{a}}$ & $3.55 \pm 0.08^{c}$ & $2.05 \pm 0.09^{c}$ \\
\hline 143 & $96.57 \pm 0.05^{\mathrm{a}}$ & $-0.13 \pm 0.05^{\mathrm{a}}$ & $3.09 \pm 0.08^{\mathrm{a}, \mathrm{b}}$ & $1.69 \pm 0.08^{b}$ \\
\hline
\end{tabular}

Means \pm SD values are presented. Different letters within the same column indicate significant differences $(p<0.05)$.

starch ones, although in all cases the moulding ratio (filmogenic suspensions weight/plate area) remained constant (Table 1). The possible agglomeration of the synthesized AgNPs, evidenced by both TEM and SEM and the increased solid content, could explain this result.

Table 2 indicates that AgNPs incorporation caused a significantly $(p<0.01)$ high reduction in the WVP, but no significant effects were observed at concentrations greater than $28.6 \mathrm{ppm}$. This behavior could be attributed to the increased tortuosity of the polymeric matrix. A similar trend was observed by Cheviron, Gouanvé, and Espuche (2015) working on potato starch based films containing silver nanoparticles submitted to a thermal treatment. With regard to other nanocomposite films, tortuosity has been mentioned as the main factor that allows to explain the films barrier properties improvement (Abreu et al., 2015; Kanmani \& Rhim, 2014a; Rhim et al., 2013b). Likewise, Ludueña, Vázquez, and Alvarez (2012) indicated that the transmission of water vapor through a material is a balance of three main mechanisms: the film crystallinity, the tortuous pathways through the polymeric matrix and the presence of structural defects on the surface.

In order to get an insight into film microstructure SEM analysis was performed. SEM micrographs of nanocomposite films (Fig. 3) show that they were homogeneous, smooth and uniform, without any crack, pore or imperfection in the surface, regardless of the addition of the NPs and their concentration. Besides, no glycerol migration was detected, indicating the polymer-plasticizer compatibility. Thus SEM observations allow to explain the low WVP results.

On the other hand, the values obtained for film solubility in water at different temperatures are presented in Table 2.

In general the film solubility decreased with increasing AgNPs content, being this significant $(p<0.05)$ at $25^{\circ} \mathrm{C}$ and becoming very significant $(p<0.01)$ at $100{ }^{\circ} \mathrm{C}$. At $25^{\circ} \mathrm{C}$ films were in average $31 \%$ soluble, while at $100{ }^{\circ} \mathrm{C}$ control films were completely soluble and nanocomposite ones were solubilized $45 \%$ in average. This behavior could be attributed to the addition of AgNPs which generate a more ordered structure in the polymer matrix, allowing to maintain their integrity, which could be indicative of the nanoparticles reinforcing effect. The solubility results were consistent with those of water vapor permeability previously described.

\subsubsection{Mechanical properties and film microstructure}

Stress-strain curves of control films showed that their mechanical behavior corresponds to a ductile and flexible material. 

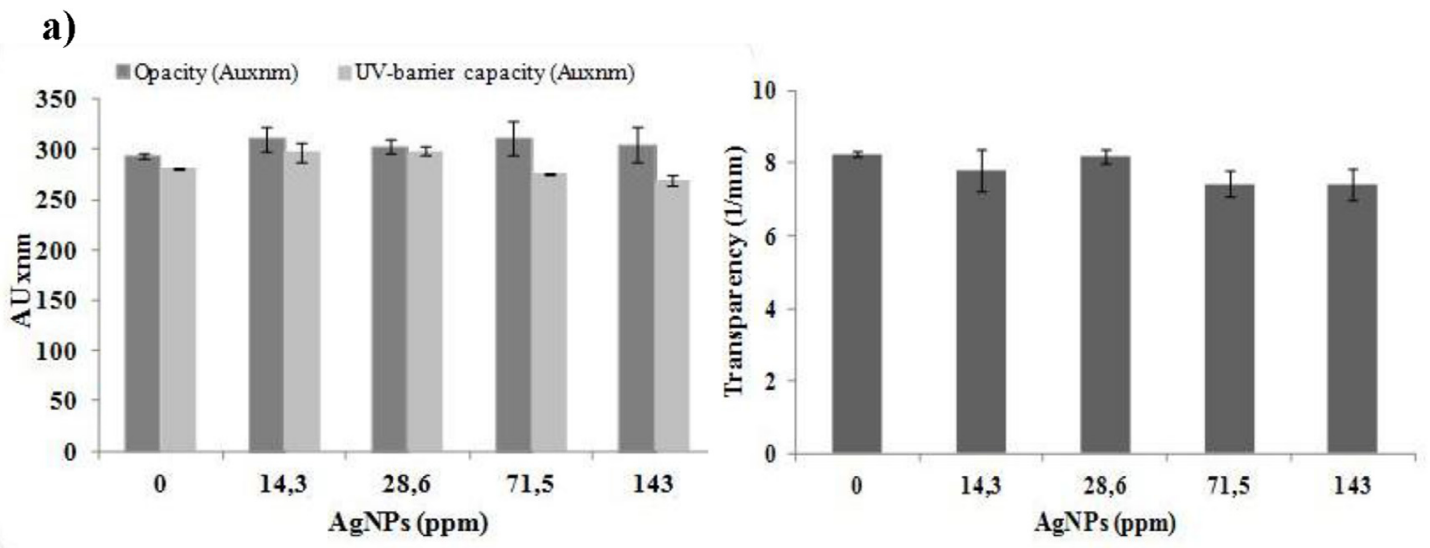

b)

AgNPs concentration in nanocomposite films (ppm)

\begin{tabular}{|c|c|c|c|c|}
\hline 0 & 14,3 & 28,6 & 71,5 & 143 \\
\hline $\begin{array}{l}\text { - El forosensibilizador en esta } \\
\text { sustrato apropiado }(\mathrm{BioH}) \text { pal } \\
\text { también pueden reaccionar ce } \\
\text { especies reactivas de oxigeno } \\
\text { - En las reacciones tipo II la e } \\
\text { de oxigeno molecular singlete } \\
\text { - Ambas reacciones conducer } \\
\text { de sustratos de origen biológ } \\
\text { consecuente inactivación celu }\end{array}$ & 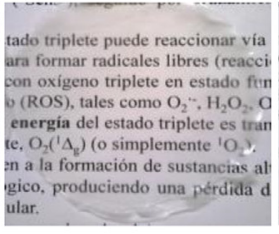 & $\begin{array}{l}\text { ransferencia de protón o electrón } \\
\text { n fotoquimica tipo I. Estos interm } \\
\text { famental }\left(\mathrm{O}_{2}\right) \text { para generar una mo } \\
\text { f. } \\
\text { ferida a ' } \mathrm{O}_{2} \text {, con la consecuente fo } \\
\text { imente reactivas que atacan a una } \\
\text { funcionalidad en las biomoléeula } \\
\text { a relación entre ambos depe }\end{array}$ & 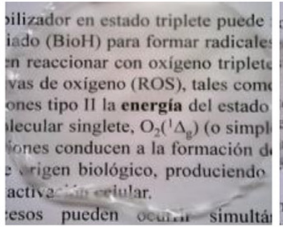 & $\begin{array}{l}\text { Pnar via transferencia de prot } \\
\text { (reacción fotoquímica tipo 1). } \\
\text { tado fundamental }\left(\mathrm{O}_{2} \text { ) para g }\right. \\
\mathrm{H}_{2} \mathrm{O}_{2}, \mathrm{OH} \text { : } \\
\text { e es transferida a }{ }^{3} \mathrm{O}_{2} \text {, con la ec } \\
\mathrm{O}^{\prime} \mathrm{O}_{2} \text { ). } \\
\text { ncias altamente reactivas que, } \\
\text { rodida de funcionalidad en las } \\
\text { te y la relación entre a }\end{array}$ \\
\hline
\end{tabular}

Fig. 2. Opacity, UV-barrier capacity and transparency of AgNPs-corn starch nanocomposite films.

Table 2

Values of thickness, water vapor permeability (WVP) and solubility at 25 and $100{ }^{\circ} \mathrm{C}$ for nanocomposite and control films.

\begin{tabular}{|c|c|c|c|c|}
\hline \multirow[t]{2}{*}{ AgNPs concentration in nanocomposite films (ppm) } & \multirow[t]{2}{*}{ Thickness $(\mu \mathrm{m})$} & \multirow[t]{2}{*}{ WVP $\left(\times 10^{-10} \mathrm{~g} / \mathrm{m} \mathrm{s} \mathrm{Pa}\right)$} & \multicolumn{2}{|c|}{ Water solubility (\%) } \\
\hline & & & At $25^{\circ} \mathrm{C}$ & At $100{ }^{\circ} \mathrm{C}$ \\
\hline 0 & $87.90 \pm 5.0^{\mathrm{a}}$ & $2.9 \pm 0.2^{c}$ & $39.2 \pm 4.9^{c}$ & $100.0 \pm 0.0^{\mathrm{d}}$ \\
\hline 14.3 & $103.0 \pm 5.9^{b}$ & $2.2 \pm 0.1^{b}$ & $34.4 \pm 0.2^{\mathrm{b}}$ & $34.8 \pm 0.8^{\mathrm{a}}$ \\
\hline 28.6 & $91.30 \pm 6.1^{\mathrm{a}}$ & $1.6 \pm 0.3^{\mathrm{a}}$ & $30.9 \pm 2.5^{\mathrm{a}}$ & $43.3 \pm 4.1^{\mathrm{b}}$ \\
\hline 71.5 & $103.6 \pm 5.6^{\mathrm{b}}$ & $1.9 \pm 0.3^{\mathrm{b}, \mathrm{a}}$ & $28.8 \pm 1.6^{\mathrm{a}}$ & $48.4 \pm 7.1^{\mathrm{b}, \mathrm{c}}$ \\
\hline 143 & $102.0 \pm 6.7^{\mathrm{b}}$ & $1.9 \pm 0.1^{\mathrm{b}, \mathrm{a}}$ & $29.0 \pm 0.5^{\mathrm{a}}$ & $52.4 \pm 2.6^{c}$ \\
\hline
\end{tabular}

Means \pm SD values are presented. Different letters within the same column indicate significant differences $(p<0.05)$.

Meanwhile those of nanocomposite films containing $143 \mathrm{ppm}$ AgNPs were associated to a stronger material, indicating that nanoparticles act as reinforcing inorganic agent of the polymeric matrix. Mechanical parameters such as tensile strength (TS), elastic modulus (EM), elongation at break (EB) and tensile energy at break (TB) are shown in Table 3. Films containing AgNPs up to $71.5 \mathrm{ppm}$ concentrations exhibited significantly $(p<0.01)$ higher tensile strength than control ones, evidencing the matrix reinforcement. Likewise in this nanocomposite films elongation at break remained practically constant (around 40\%), leading to resistant and tough materials. Rhim et al. (2013b) also observed onto agar/silver nanoparticles composite films a similar mechanical behavior, and attributed the increased in TS with AgNPs content to the physical attraction of the components. A similar trend was informed by Ji, Liu, Zhang, Xiong, and Sun (2016) working on corn starch films containing AgNPs ( $2-8 \mathrm{mg} / \mathrm{g}$ ) obtained by chemical reduction and stabilized by short chains glucan.

Table 3 also shows that the area under the force-distance curve, which is related to the traction energy needed to test probe rupture (Sarantopoulos et al., 2002), showed a significant $(p<0.01)$ increase in nanocomposite films compared to control.

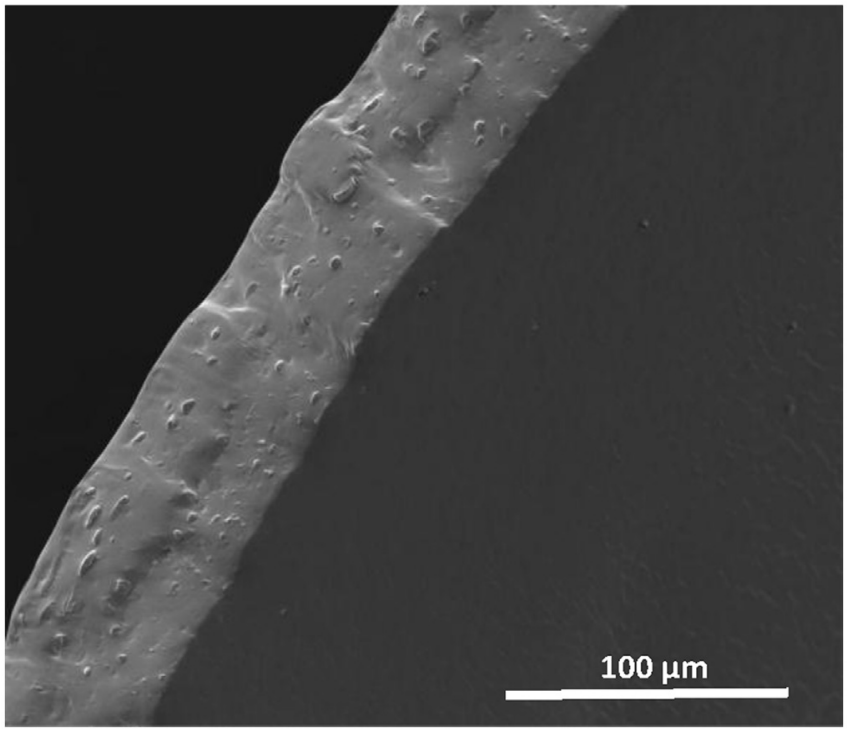

Fig. 3. SEM cross-sections morphology of corn starch nanocomposite films containing 143 ppm AgNPs. 
Table 3

Mechanical parameters for nanocomposite films.

\begin{tabular}{|c|c|c|c|c|}
\hline AgNPs concentration in nanocomposite films (ppm) & Elongation at break (\%) & Tensile strength (MPa) & Elastic Modulus (MPa) & Tensile energy at break (J) \\
\hline 0 & $39.7 \pm 0.1^{\mathrm{a}}$ & $27.4 \pm 0.9^{\mathrm{a}}$ & $32.7 \pm 8.0^{\mathrm{a}}$ & $134.6 \pm 10.5^{\mathrm{a}}$ \\
\hline 14.3 & $39.7 \pm 0.1^{\mathrm{a}}$ & $29.5 \pm 2.5^{\mathrm{a}, \mathrm{b}}$ & $36.9 \pm 10.3^{a}$ & $161.6 \pm 13.7^{b}$ \\
\hline 28.6 & $38.1 \pm 2.1^{\mathrm{a}}$ & $30.2 \pm 0.6^{\mathrm{b}}$ & $41.6 \pm 9.3^{\mathrm{a}, \mathrm{b}}$ & $181.2 \pm 10.3^{\mathrm{b}, \mathrm{c}}$ \\
\hline 71.5 & $39.6 \pm 0.1^{a}$ & $31.4 \pm 1.4^{\mathrm{b}}$ & $57.9 \pm 6.8^{\mathrm{b}}$ & $191.7 \pm 9.5^{\mathrm{c}}$ \\
\hline 143 & $39.0 \pm 0.8^{\mathrm{a}}$ & $58.5 \pm 2.4^{c}$ & $166.8 \pm 41.7^{c}$ & $368.1 \pm 58.3^{d}$ \\
\hline
\end{tabular}

Means \pm SD values are presented. Different letters within the same column indicate significant differences $(p<0.05)$.

The elastic modulus is an indicator of the film rigidity, the higher the modulus the stiffer the material. A significant effect $(p<0.05)$ in the elastic modulus by the addition of AgNPs, confirmed the matrix reinforcing of the nanocomposite films (Table 3). In the same way, Kuorwel et al. (2015) stressed that improvements in the mechanical properties were obtained when AgNPs were incorporated to chitosan based films containing poly (hydroxyalkanoate) (PHA) and poly (lactic acid) (PLA). It has also been reported that LDPE nanocomposite silver decreases their elongation at break (Metak, Nabhani, \& Connolly, 2015). Similar trends were reported by Yoksan and Chirachanchai (2010) working on chitosan-starch films containing higher concentrations of AgNPs (0.15-0.29\% w/w).

In Fig. 4 the micrographs of surface topography and cross-sections of the films submitted to tension mechanical assays and studied by SEM are observed. Control films exhibited cracks or micro-cracks in the material surface aligned in the direction in which the fracture of the specimen are spread (Fig. 4a). This morphology corresponds to the mechanical behavior observed for this material, with high elongations (around 40\%) and low stresses (approximately $20 \mathrm{MPa}$ ).
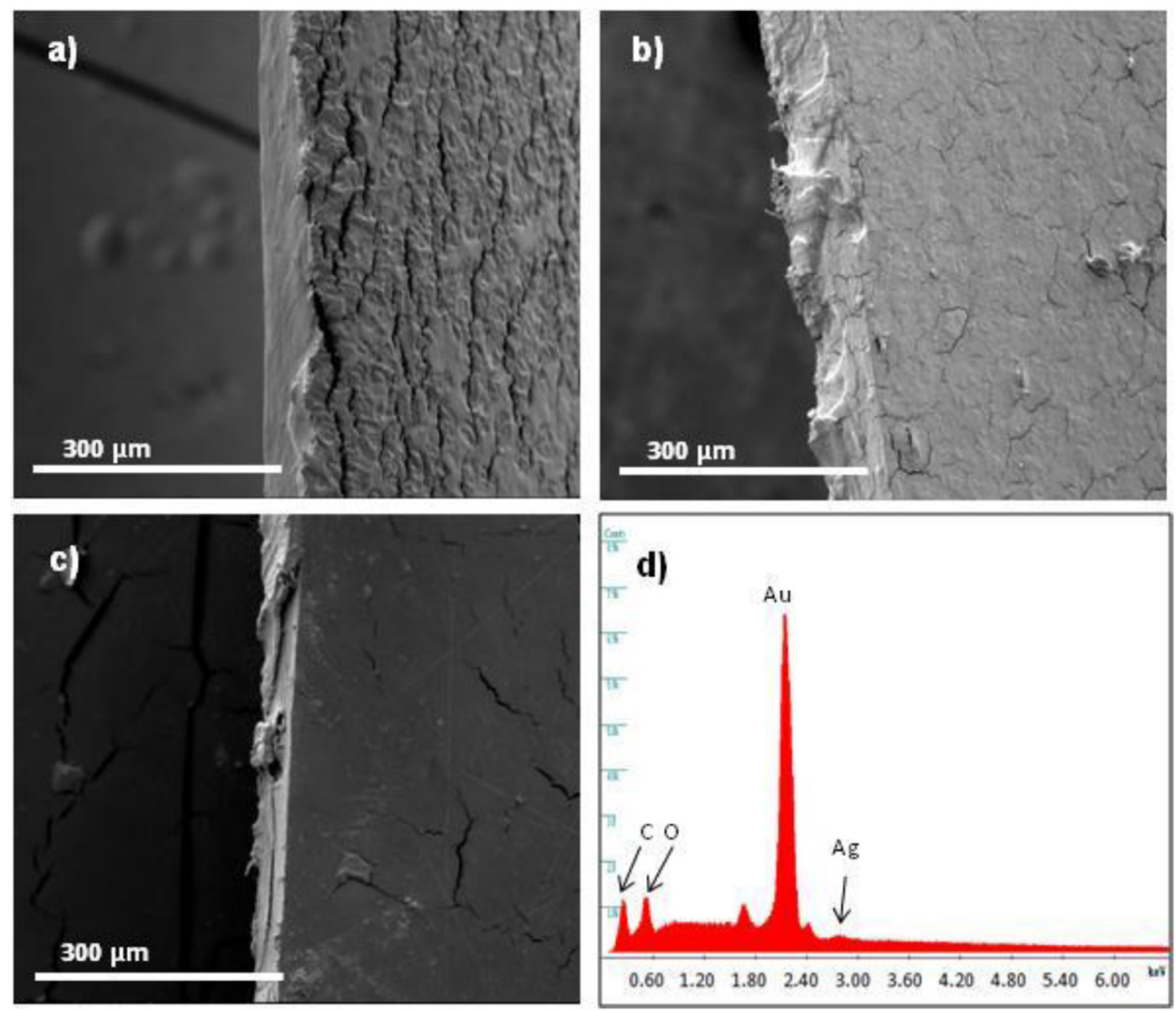

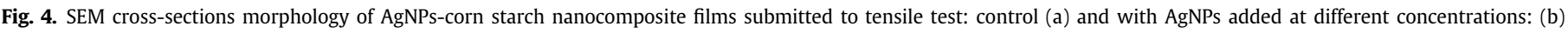
28,6 ppm and (c) $143 \mathrm{ppm}$. (d) EDS spectrum of the cross-section of 28,6 ppm AgNPs film.

Fig. 4b micrograph corresponds to the film with $28.6 \mathrm{ppm}$ AgNPs after tensile test and shows a more compact cross-sections and a marked decrease in the cracks number. Likewise the alignment pattern thereof in the direction of the fracture previously described was not evidenced in this case. These observations are in agreement with the mechanical properties results of these nanoreinforced materials, in which elongation remained practically constant and a slight increase in both tensile strength and elastic modulus was obtained with the addition of up to $28.6 \mathrm{ppm}$ of AgNPs. When AgNPs concentration increased to $143 \mathrm{ppm}$, the film microstructure changed again (Fig. 4c). Cross-sections of these nanocomposite films submitted to tensile test show a more compact structure with a limited number of cracks in the surface, some of which are oriented in the direction of fracture propagation. Again, film microstructure analysis correlates with mechanical results since, with the addition of NPs, the elongation at break was maintained while tensile strength significantly $(p<0.05)$ increased (about $60 \mathrm{MPa}$ ) as well as both the elastic modulus and the energy associated to the tensile rupture.

EDS spectroscopy corroborated the presence of elemental $\mathrm{Ag}$ in 


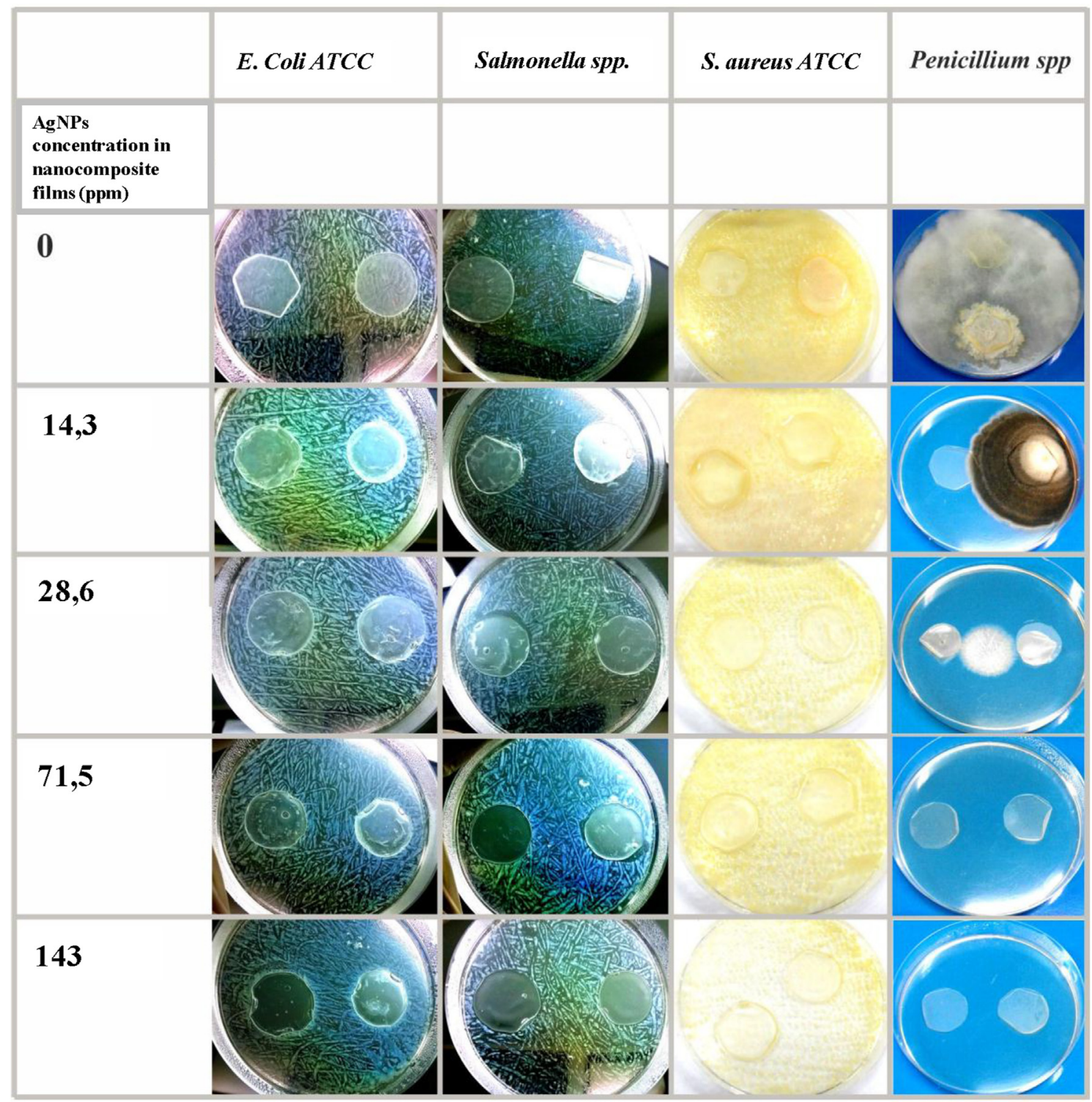

Fig. 5. Growth inhibition of E.coli ATCC, Salmonella spp., S.aureus ATCC and Penicillium spp. of AgNPs-corn starch nanocomposite films.

developed nanocomposite materials. Bindhu and Umadevi (2013) reported that AgNPs exhibit a typical absorption peak at $\sim 3 \mathrm{keV}$ due to their strong surface plasmon resonance (SPR) transition. As expected, the major elements detected in control samples were $C$ and $\mathrm{O}$, attributed to starch, as well as an important signal for Au due to the sample metallization (Fig. 3d). In nanocomposite films, such as that containing $28.6 \mathrm{ppm}$ AgNPs, a weak signal (due to its low concentration) at about $3 \mathrm{keV}$ was detected, indicating the presence of $\mathrm{Ag}$ in the film cross-sections. Other authors also evidenced AgNPs in nanocomposite films using EDS spectroscopy (Kanmani \& Rhim, 2014a).

\subsection{Evaluation of antimicrobial capacity}

Antimicrobial properties of control and nanocomposite films containing 143, 71.5, 28.6 or 14.3 ppm AgNPs were evaluated by an agar disc diffusion method against E. coli, S. aureus, Salmonella and Penicillium.

Fig. 5 shows the test photographs after incubation at $37{ }^{\circ} \mathrm{C}$ for
$72 \mathrm{~h}$ in the case of bacteria, and 7 days for Penicillium. The results revealed that the nanocomposite films presented antimicrobial activity in the contact area under de film. The absence of inhibition halo suggests that no diffusion of the active compound occurred to the agar medium, assuming a good entrapment of the AgNPs in the film matrix (Abreu et al., 2015). This result can be associated with the low AgNPs concentration used compared to other authors. Yoksan and Chirachanchai (2010) reported that clear inhibitory zones larger than $28 \mathrm{~mm}$ were observed in chitosan-starch films using high silver nanoparticles concentrations from 0.07 to $0.29 \%$ $(\mathrm{w} / \mathrm{w})$.

Growth inhibition of E. coli and Salmonella was appreciable for films with AgNPs concentrations from $71.5 \mathrm{ppm}$ to $28.6 \mathrm{ppm}$, respectively. No inhibition of microbial growth was observed for S. aureus, neither under the film contact area, only a marked decrease in the plate growth was observed for $143 \mathrm{ppm}$ AgNPs films. These results can be associated with the different structure of the outer membrane and peptidoglycan layer, thus being more sensitive Gram-negative bacteria (E. coli and Salmonella) to silver 


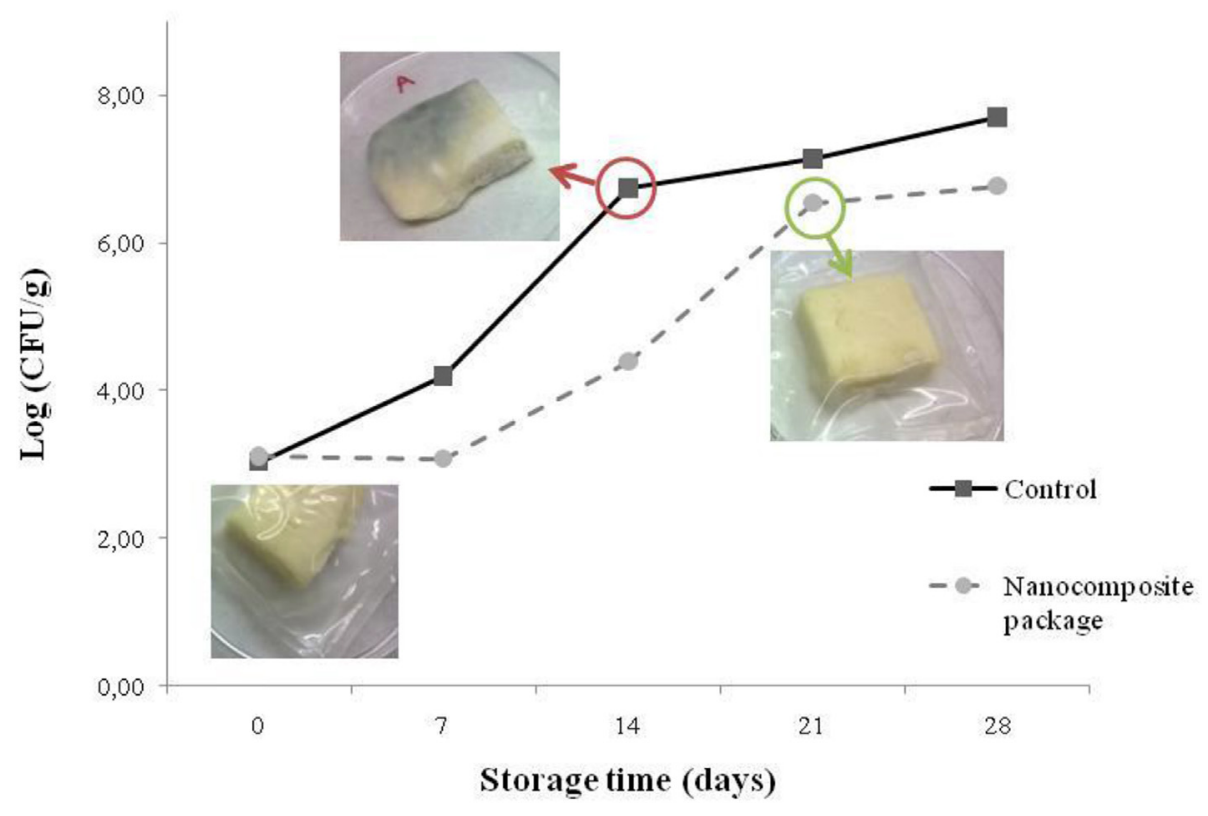

Fig. 6. Nanocomposite films effect on shelf-life of fresh cheese samples stored at $4{ }^{\circ} \mathrm{C}$.

nanoparticles, than that Gram-positive ones (S. aureus) (Kim et al., 2007; Raghavendra, Jung, Kim, \& Seo, 2016; Yoksan \& Chirachanchai, 2010).

With regard to Penicillium spp., a reduction of fungal growth was observed for films containing $28.6 \mathrm{ppm}$ AgNPs and the complete inhibition occurred for higher concentrations to $71.5 \mathrm{ppm}$.

The mechanism of the growth inhibition of microorganisms by the AgNPs is still unclear. Some evidence suggests that the antimicrobial activity of silver nanoparticles may be due to interacting with the bacterial membrane components causing damage and structural changes that lead to cell death (Kim et al., 2007; Marambio-Jones \& Hoek, 2010). Likewise, Morones et al. (2005) suggested that AgNPs could interact with phosphorous and sulfur containing compounds of proteins and DNA, preventing DNA replication, and leading to cell death.

In these kinds of nanomaterials the release of silver ions increases the permeability of the plasma membrane, the proton motive force loss, thereby decreasing the energy of the cells; thus, AgNPs could act as reservoirs for silver ions (Feng et al., 2000). Meanwhile some authors have indicated that can alter DNA replication and expression of enzymes associated with the production of ATP (Marambio-Jones \& Hoek, 2010; Pal, Tak, \& Song, 2007; Raghavendra et al., 2016).

\subsection{Applications of active films}

For antimicrobial capacity studies the 143 ppm AgNPs concentration was selected, since the derived films provide antimicrobial activity as well as they maintain better appearance with improved barrier and mechanical properties.

In order to obtain active packaging, thermo-sealing capacity of nanocomposite films was analyzed. The addition of AgNPs did not change the thermo-sealed capacity of the films. The predominant mode of failure was caused by delamination of the thermosealing, while that of control films was adhesive. Control films exhibited a mean resistance value of $1.66 \pm 0.2 \mathrm{MPa}$ with a maximum resistance of $2.67 \pm 0.4 \mathrm{MPa}$. The energy necessary to break the thermosealed could be calculated only in the case of adhesive failure, being $0.59 \pm 0.13 \mathrm{~J}$ for control films. For nanocomposite films the mean resistance value $(1.30 \pm 0.17 \mathrm{MPa})$ obtained indicates that a resistant zip was obtained. Considering that the integrity of a package depends on the quality of their zip, a good sealing is obtained when the molecular interaction between individual layers is enough to destroy the interface leading to a new homogenous layer (Cho, Ullsten, Gällstedt, \& Hedenqvist, 2007). Similarly, López et al. (2011) studied the heat sealing capacity of native starch films and observed that the necessary energy to break the thermosealed is $0.224 \pm 0.003 \mathrm{~J}$.

In order to evaluate the effectiveness of the developed films, pieces of cheese were packed and their shelf-life under refrigeration conditions were evaluated by microbiological assays. The fresh cheese was a few fermented product, but slightly acid $(\mathrm{pH} \approx 5)$ with high water activity, a low percentage of salt $(<3 \%)$ and electronegative redox potential (absence of oxygen), allowing the development of many microorganisms, especially fungi and yeasts. Thus, product shelf-life was evaluated by counts of molds and yeasts presents and it was defined as the time required to reach $10^{6} \mathrm{CFU} / \mathrm{g}$ of sample (López et al., 2011). Considering this value, the shelf-life was 14 days for the control sample, whereas the one packaged with the nanocomposite film shows an average shelf-life of 21 days (Fig. 6).

The obtained results indicate the effectiveness of nanocomposite films for food packaging, although cytotoxic tests are required. Regarding this aspect, Abreu et al. (2015) carried out a contact-test assay using different food simulants to determine if the nanostructured starch films fulfill with the regulations and European directives on food packaging and observed that the migration of $\mathrm{Ag}$ was not significant. Their results are in agreement with the antimicrobial test performed, were the absence of an inhibition halo demonstrates the entrapment of active compounds. Considering this preliminary test, the above data indicated that nanocomposite films would be safe and could be used in food contact. Likewise, Metak et al. (2015) working on polyethylene packaging containing $1 \%$ AgNPs studied the migration of nanoparticles from packaging into different food simulants and real foods samples. They stressed that these materials appears to be safe for food packaging since insignificant levels of nano-silver were released and no organoleptic changes were observed. However, more 
researches on the migration of AgNPs in contact with food materials are needed.

\section{Conclusions}

AgNPs were synthesized directly into the filmogenic starch suspension by a simple method, easy to implement, coupling both the nanoparticles synthesis and preparation of the biodegradable material. The obtaining of these films in one step could facilitate the scaling-up of their production at industrial level. Furthermore the use of a non-toxic reducing agent to synthesize silver particles maintains the eco-friendly character of starch films.

Synthesized nanoparticles were spherical with diameters varying between 5 and $20 \mathrm{~nm}$. The addition of AgNPs did not affect the filmogenic capacity of gelatinized corn starch suspension, neither their UV barrier capacity nor heat sealing ability. Optically, the nanocomposite films obtained were homogeneous and colorless. With regard to the barrier properties, a decrease in water vapor permeability with increasing concentration of AgNPs was observed. Besides, AgNPs incorporation contributed to the matrix reinforcement, since more resistant and tough materials were developed.

Nanocomposite films exhibited strong antimicrobial activity against Salmonella spp., E. coli and Penicillium spp, therefore, they are expected to have high potential for the use as active food packaging materials. In this sense, films containing 143 ppm AgNPs were selected to evaluate their effect on the shelf-life of a dairy product. These active films were able to extend the shelf-life of fresh cheese samples for 21 days. However, it is important to note that for future applications in food, tests on the AgNPs toxicity and migration to the product are necessary.

\section{References}

Abreu, A. S., Oliveira, M., de Sá, A., Rodrigues, R. M., Cerqueira, M. A., Vicente, A. A. et al. (2015). Antimicrobial nanostructured starch based films for packaging Carbohydrate Polymers, 129, 127-134.

Bertuzzi, M. A., Gottifredi, J. C., \& Armada, M. (2012). Mechanical properties of a high amylose content corn starch based film, gelatinized at low temperature. Brazilian Journal of Food Technology, 15, 219-227.

Bindhu, M. R., \& Umadevi, M. (2013). Synthesis of monodispersed silver nanoparticles using Hibiscus cannabinus leaf extract and its antimicrobial activity. Spectrochimica Acta A: Molecular and Biomolecular Spectroscopy, 101, 184-190.

Cheng, F., Betts, J. W., Kelly, S. M., \& Hector, A. L. (2015). Green synthesis of highly concentrated aqueous colloidal solutions of large starch-stabilised silver nanoplatelets. Materials Science and Engineering C, 46, 530-537.

Cheng, F., Betts, J. W., Kelly, S. M., Schallerb, J., \& Heinze, T. (2013). Synthesis and antibacterial effects of aqueous colloidal solutions of silver nanoparticles using aminocellulose as a combined reducing and capping reagent. Green Chemistry, 15, 989-998.

Cheviron, P., Gouanvé, F., \& Espuche, E. (2014). Green synthesis of colloid silver nanoparticles and resulting biodegradable starch/silver nanocomposites. Carbohydrate Polymers, 108, 291-298.

Cheviron, P., Gouanvé, F., \& Espuche, E. (2015). Starch/silver nanocomposite: Effect of thermal treatment temperature on the morphology, oxygen and water transport properties. Carbohydrate Polymers, 134, 635-645.

Cheviron, P., Gouanvé, F., \& Espuche, E. (2016). Preparation, characterization and barrier properties of silver/montmorillonite/starch nanocomposite films. Journal of Membrane Science, 497, 162-171.

Cho, S., Ullsten, H., Gällstedt, M., \& Hedenqvist, M. (2007). Heat-sealing properties of compression-molded wheat gluten films. Journal of Biobased Material and Bioenergy, 1, 56-63.

Daniel, M. C., \& Astruc, D. (2004). Gold nanoparticles: Assembly, supramolecular chemistry, quantum-size-related properties, and applications toward biology, catalysis, and nanotechnology. Chemical Reviews, 104, 293-346.

Feng, Q. L., Wu, J., Chen, G. Q., Cui, F. Z., Kim, T. N., \& Kim, J. O. (2000). A mechanistic study of the antibacterial effect of silver ions on Escherichia coli and Staphylococcus aureus. Journal of Biomedical Materials Research Part A, 5, 2662-2668.

Flores, C. Y., Miñ̃n, A. G., Grillo, C. A., Salvarezza, R. C., Vericat, C., \& Schilardi, P. L. (2013). Citrate-capped silver nanoparticles showing good bactericidal effect against both planktonic and sessile bacteria and a low cytotoxicity to osteoblastic cells. ACS Applied Materials \& Interfaces, 5, 3149-3159.

García, M. A., Martino, M. N., \& Zaritzky, N. E. (2001). Composite starch-based coatings applied to strawberries (Fragaria ananassa). Nahrung/Food, 45,
267-272.

García, M. A., Pinotti, A., \& Zaritzky, N. E. (2006). Physicochemical, water vapor barrier and mechanical properties of corn starch and chitosan composite films. Starch/Stärke, 58, 453-463.

Ghosh, S., Kaushik, R., Nagalakshmi, K., Hoti, S. L., Menezes, G. A., Harish, B. N., et al. (2010). Antimicrobial activity of highly stable silver nanoparticles embedded in agar-agar matrix as a thin film. Carbohydrate Research, 345, 2220-2227.

Gontard, N., Guilbert, S., \& Cuq, J. L. (1992). Edible wheat gluten films: Influence of the main process variables on film properties using response surface methodology. Journal of Food Science, 57, 190-195.

Hackenberg, S., Scherzed, A., Kessler, M., Hummel, S., Technau, A., Froelich, K., et al. (2011). Silver nanoparticles: Evaluation of DNA damage, toxicity and functional impairment in human mesenchymal stem cells. Toxicology Letters, 201, 27-33.

Ji, N., Liu, C., Zhang, S., Xiong, L., \& Sun, Q. (2016). Elaboration and characterization of corn starch films incorporating silver nanoparticles obtained using short glucan chains. LWT - Food Science and Technology, 74, 311-318.

Kanmani, P., \& Rhim, J. W. (2014a). Physical, mechanical and antimicrobial properties of gelatin based active nanocomposite films containing AgNPs and nanoclay. Food Hydrocolloids, 35, 644-652.

Kanmani, P., \& Rhim, J. W. (2014b). Physicochemical properties of gelatin/silver nanoparticle antimicrobial composite film. Food Chemistry, 148, 162-169.

Kerker, M. (1985). The optics of colloidal silver: Something old and something new. Journal of Colloid and Interface Science, 105, 297-314.

Kim, J. S., Kuk, E., Yu, K. N., Kim, J. H., Park, S. J., Lee, H. J., et al. (2007). Antimicrobial effects of silver nanoparticles. Nanomedicine: Nanotechnology, Biology, and Medicine, 3, 95-101.

Kuorwel, K. K., Cran, M. J., Orbell, J. D., Buddhadasa, S., \& Bigger, S. W. (2015). Review of mechanical properties, migration, and potential applications in active food packaging systems containing nanoclays and nanosilver. Comprehensive Reviews in Food Science and Food Safety, 14, 411-430.

López, O. V., García, M. A., \& Zaritzky, N. E. (2008). Film forming capacity of chemically modified corn starches. Carbohydrate Polymers, 73, 573-581.

López, O. V., Giannuzzi, L., Zaritzky, N. E., \& García, M. A. (2013). Potassium sorbate controlled release from corn starch films. Materials Science and Engineering C, 33, 1583-1591.

López, O. V., Lecot, C. J., Zaritzky, N. E., \& García, M. A. (2011). Biodegradable packages development from starch based heat sealable film. Journal of Food Engineering, 105, 254-263.

Ludueña, L., Vázquez, A., \& Alvarez, V. (2012). Effect of lignocellulosic filler type and content on the behavior of polycaprolactone based eco-composites for packaging applications. Carbohydrate Polymers, 87, 411-421.

Marambio-Jones, C., \& Hoek, E. M. (2010). A review of the antibacterial effects of silver nanomaterials and potential implications for human health and the environment. Journal of Nanoparticle Research, 12, 1531-1551.

Masala, O., \& Seshadri, R. (2004). Synthesis routes for large volumes of nanoparticles. Annual Review of Materials Research, 34, 41-81.

Metak, A. M., Nabhani, F., \& Connolly, S. N. (2015). Migration of engineered nanoparticles from packaging into food products. LWT - Food Science and Technology, 64, 781-787.

Morones, J. R., Elechiguerra, J. L., Camacho, A., Holt, K., Kouri, J. B., Tapia Ramırez, J., et al. (2005). The bactericidal effect of silver nanoparticles. Nanotechnology, 16, 2346-2353.

Olivato, J. B., Marini, J., Yamashita, F., Pollet, E., Grossmann, M. V. E., \& Avérous, L. (2017). Sepiolite as a promising nanoclay for nano-biocomposites based on starch and biodegradable polyester. Materials Science and Engineering C, 70, 296-302.

Oluwafemi, O. S., Vuyelwa, N., Scriba, M., \& Songca, S. P. (2013). Green controlled synthesis of monodispersed, stable and smaller sized starch-capped silver nanoparticles. Materials Letters, 106, 332-336.

Pal, S., Tak, Y. K., \& Song, J. M. (2007). Does the antibacterial activity of silver nanoparticles depend on the shape of the nanoparticle? a study of the gramnegative bacterium Escherichia coli. Applied and Environmental Microbiology, 73, 1712-1720.

Pranoto, Y., Rakshit, S. K., \& Salokhe, V. M. (2005). Enhancing antimicrobial activity of chitosan films by incorporating garlic oil, potassium sorbate and nisin. LWTFood Science and Technology, 38, 859-865.

Raghavendra, G. M., Jung, J., Kim, D., \& Seo, J. (2016). Step-reduced synthesis of starch-silver nanoparticles. International Journal of Biological Macromolecules, $86,126-128$.

Raveendran, P., Fu, J., \& Wallen, S. L. (2003). Completely "green" synthesis and stabilization of metal nanoparticles. Journal of the American Chemical Society, $125,13940-13941$.

Rhim, J. W., Hong, S. I., Park, H. M., \& Perry, K. W. N. G. (2006). Preparation and characterization of chitosan-based nanocomposite films with antimicrobial activity. Journal of Agricultural and Food Chemistry, 54, 5814-5822.

Rhim, J. W., Park, H. M., \& Hac, C. S. (2013). Bio-nanocomposites for food packaging applications. Progress in Polymer Science, 38, 1629-1652.

Rhim, J. W., Wang, L. F., \& Hong, S. I. (2013). Preparation and characterization of agar/silver nanoparticles composite films with antimicrobial activity. Food $\mathrm{Hy}$ drocolloids, 33, 327-335.

Sarantopoulos, C., de Oliveira, M., Padula, M., Coltro, L., Vercelino Alves, R. M., \& Correa García, E. (2002). Embalagens Plásticas Flexíveis. Campinas, Brasil: Centro de Tecnología de Embalagem.

Slistan-Grijalva, A., Herrera-Urbina, R., Rivas-Silva, J. F., Avalos-Borja, M., CastillónBarraza, F. F., \& Posada-Amarillas, A. (2005). Classical theoretical 
characterization of the surface plasmon absorption band for silver spherical nanoparticles suspended in water and ethylene glycol. Physica E: Lowdimensional Systems and Nanostructures, 27, 104-112.

Vigneshwaran, N., Nachane, R. P., Balasubramanya, R. H., \& Varadarajan, P. V. (2006). A novel one-pot 'green' synthesis of stable silver nanoparticles using soluble starch. Carbohydrate Research, 341, 2012-2018.

Wang, K., Wang, W., Ye, R., Liu, A., Xiao, J., Liu, Y., et al. (2017). Mechanical properties and solubility in water of corn starch-collagen composite films: Effect of starch type and concentrations. Food Chemistry, 216, 209-216.

Yoksan, R., \& Chirachanchai, S. (2010). Silver nanoparticle-loaded chitosan-starch based films: Fabrication and evaluation of tensile, barrier and antimicrobial properties. Materials Science and Engineering C, 30, 891-897.

Zhang, Y., \& Han, J. H. (2006). Mechanical and thermal characteristics of pea starch films plasticized with monosaccharides and polyols. Journal of Food Science, 71 109-118.

Zhang, Y., Peng, H., Huang, W., Zhou, Y., \& Yan, D. (2008). Facile preparation and characterization of highly antimicrobial colloid Ag or Au nanoparticles. Journal of Colloid and Interface Science, 325, 371-376.

Zolfi, M., Khodaiyan, F., Mousavi, M., \& Hashemi, M. (2014). The improvement of characteristics of biodegradable films made from kefiran-whey protein by nanoparticle incorporation. Carbohydrate Polymers, 109, 118-125. 